\title{
LEAD CONTAMINATION OF FRUIT SPIRITS INTENDED FOR OWN CONSUMPTION AS A POTENTIAL OVERLOOKED PUBLIC HEALTH ISSUE? A PILOT STUDY
}

\author{
Mária Tatarková1, Tibor Baška', Miroslava Sovičová1, Stanislav Kuka', Eliška Štefanová1, Martin Novák', Barbora \\ Váňová2, Henrieta Hudečková ${ }^{1}$ \\ ${ }^{1}$ Department of Public Health, Jessenius Faculty of Medicine in Martin, Comenius University, Martin, Slovak Republic \\ ${ }^{2}$ Department of Molecular Biology, Jessenius Faculty of Medicine in Martin, Comenius University, Martin, Slovak Republic
}

\begin{abstract}
SUMMARY
Objective: The aim of the study was to analyse the occurrence of lead in selected samples of fruit distilled spirits for own consumptions in terms of possible contribution to the occurrence of alcohol-attributable diseases.

Methods: In a pilot study, we analysed 18 samples of fruit spirits for own consumption. Most of the samples were distilled in the local growing distilleries in the Žilina Region with exception of 3 samples collected in the Trnava Region (one of them was of Hungarian origin). Sample preparation included previous mineralization with use of microwave decomposition system Multiwave $6050 \mathrm{~Hz}$. The samples were analysed by atomic absorption spectroscopy with graphic furnace (AAS GBC XplorAA 5000 with GF 5000).

Results: The average ethanol level in our samples was higher in comparison with distributed spirits. We detected lead in all samples. In two of them the concentration was lower than the limit of quantitation (LOQ). The highest lead concentrations were observed in plum spirit from Hungary $(581.0 \mu \mathrm{g} / \mathrm{l})$, and in grape spirit made in the Trnava Region $(466.3 \mu \mathrm{g} / \mathrm{l})$.

Conclusions: Lead is a widespread contaminant of fruit spirits prepared for own consumption. Taking into consideration its common occurrence and possible multiplicative effect with ethanol, we can assume that lead can contribute to the occurrence of several alcohol-attributable chronic diseases. Due to the insufficient information in this field, our results provide significant insight into the issue and present an important starting point for further research.
\end{abstract}

Key words: lead, fruit spirits, analysis

Address for correspondence: M. Tatarková, Department of Public Health, Jessenius Faculty of Medicine in Martin, Malá Hora 4B, 03601 Martin, Slovak Republic. E-mail: tatarkova12@uniba.sk

https://doi.org/10.21101/cejph.a5524

\section{INTRODUCTION}

Lead is a cumulative toxicant that affects multiple body systems. Lead enters the body via inhalation, ingestion or skin absorption. It is distributed in the liver and kidney as well as to the teeth and bones. More than $90 \%$ of the total body burden of this element is accumulated in the bones. Lead accumulated in bones may be further released into the bloodstream, re-exposing organ systems long after the original exposure (1).

People can become exposed to lead through occupational and environmental sources. For chronic exposure is an important ingestion of lead-contaminated food and water. The exposure has been mostly considered as a dominant issue of occupational medicine. In the past, the excessive exposure usually manifested specific signs of acute intoxications. Nowadays, such cases of intoxication are very rare in developed countries. Long-term effects of chronic exposure of lead can increase risk of high blood pressure and kidney damage (1).
In developed countries there are strict legislative mechanisms for the effective control of environmental exposure via monitoring and supervision of drinking water in public water supply, ambient air quality monitoring and supervision of processing technology in selected sectors of the food production and processing. However, some possible exposures still remain overlooked and require relevant attention. Among these sources we include fruit distilled spirits for own consumption (traditional legal product outside a regulatory framework). One of the main problems considering these products is that they are not a subject of regular governmental supervision to ensure that their composition is free of contaminants or toxic compounds potentially causing health damage. These alcohol beverages are defined as alcoholic beverages for own consumption (personal use). Because of this fact, legislation cannot control the concentration of selected heavy metals in the final product of distillation. Nowadays, the supervision of the distillation apparatus and the concentrations of methanol, ethanol and higher alcohols in final product are under the legisla- 
tive control of growing distillery. Thus, there are different levels of the legislative control of distributional spirits in trade network and distilled spirits for own consumption. Moreover, there are no uniform regulatory limits defining the maximum level of lead in distilled spirits in the European Union.

Fruit distilled spirits for own consumption have been spread worldwide. Artisanal fermented beverages and spirits have become the most common categories of alcohol beverages for own consumption globally (2). Usually, there is a higher ethanol concentration (40\%) in fruit distilled spirits for own consumption compared to recorded alcoholic beverages $(3,4,5)$. As known, there are numerous factors related to beverage quality influencing probability of acute or chronic health disorders (2-4). Among them, lead contamination can potentially contribute to these problems, as shown by experimental studies on animals $(2,6-9)$.

Data on concentration of lead in fruit distilled spirits for own consumption is necessary to understand the extent of the issue. Until now, no systematic mapping in the field has been carried out in Europe. However, results of several pilot analyses indicate relevance of the issue. Therefore, the issue has particular topicality in Central European countries characterized by the widespread production and consumption of fruit spirits produced for own consumption.

The main objective of the pilot study is to detect the presence of lead in samples of fruit spirits intended for own consumptions (for this reason there are 18 samples). The second aim of this pilot study is to determine concentrations of lead in various types of fruit spirits intended for own consumption originating in Slovakia to provide a tentative view into the issue and to estimate its potential public health significance. The results may become an important starting point for further systematic research in the field.

\section{MATERIALS AND METHODS}

\section{Samples}

In a pilot study, we analysed 18 samples of fruit spirits for own consumption (legal products outside the distribution network). Most of the samples were distilled in local growing distilleries in the Žilina Region (Northern Slovakia), except 3 samples taken in the Trnava Region (west part of Slovakia). One of the samples taken in Trnava has its origin is Hungary (Györ). The samples of distilled spirits included apples (8 samples), plums (4 samples), grapes ( 2 samples), blackthorns ( 2 samples), and apricots distillates (1 sample), as well as mix of apples and plums (1 sample).
Special cleaned bottles were used to collect samples of the distillates. Bottles were soaked in 10\% nitric acid for 24 hours with $\mathrm{HNO}_{3}$ and afterwards washed twice with ultrapure water Type $1\left(\mathrm{UP}_{2} \mathrm{O}\right)$ with minimum resistivity of $18.2 \mathrm{M} \Omega . \mathrm{cm}$. The $50 \mathrm{ml}$ samples were taken and consequently stored in the dark. The samples were transferred to the laboratory within 24 hours and were stored at $8^{\circ} \mathrm{C}$ in dark. In the first part of the analysis we determined the volume of alcohol (alcoholometric tables). In the second part, we diluted $\left(\mathrm{UP}_{2} \mathrm{O}\right)$ the samples up to $10 \%$ ethanol level and further mineralized them (to destroy the organic matrix and to extract the metal ions bound in inorganic and organic complexes) according to the recommended procedure of the microwave decomposition system manufacturer (Multiwave $6050 \mathrm{~Hz}$ ) (Table 1). Immediately before the mineralization, we prepared the $15 \mathrm{ml}$ samples consisting of $10 \mathrm{ml}$ trace metal grade (TMG) $\mathrm{HNO}_{3}$ and $5 \mathrm{ml}$ of $10 \%$ distillate. After the mineralization, the samples were stored in a fridge at $8^{\circ} \mathrm{C}$ for 48 hours. After 48 hours, samples were analysed using a graphite furnace atomic absorption spectroscopy (AAS GBC XplorAA 5000 with GF 5000) (Table 2).

\section{Instrumentation}

To identify the ethanol volume in our samples we used an analytic weight (Kern ABS-ABJ-NM). Sample preparation consisted of previous mineralization for which the microwave decomposition system (Multiwave $6050 \mathrm{~Hz}$ ) was used. The samples were analysed by atomic absorption spectroscopy with graphic furnace type AAS GBC XplorAA 5000 with GF 5000. For specific lead analysis we used hollow cathode lamp (217.0 nm wavelength, slit width of $1.0 \mathrm{~nm}$, lamp current $5 \mathrm{~mA}$ ). Deuterium background corrector facilitated proper background correction. The temperature program used to determine the lead by GF AAS is shown in Table 2 (the temperature mode has been set by the instrument manufacturer and adapted to measure the lead content in the presence of $\mathrm{HNO}_{3}$ ). Argon was used as the

Table 1. Digestion programme of alcoholic beverages for Multiwave $6050 \mathrm{~Hz}$

\begin{tabular}{|l|c|c|c|c|}
\hline Step & $\begin{array}{c}\text { Ramp time } \\
(\mathbf{m m}: \mathbf{s s})\end{array}$ & $\begin{array}{c}\text { Temperature } \\
\left({ }^{\circ} \mathbf{C}\right)\end{array}$ & $\begin{array}{c}\text { Hold time } \\
(\mathbf{m m}: \mathbf{s s})\end{array}$ & Fan \\
\hline 1 & $20: 00$ & 130 & $0: 01$ & 1 \\
\hline 2 & $5: 00$ & 180 & $5: 00$ & 1 \\
\hline 3 & & 70 & & 3 \\
\hline
\end{tabular}

Table 2. Graphite furnace temperature programme for study of $\mathrm{Pb}$ in spirits

\begin{tabular}{|l|c|c|c|c|}
\hline & Final temperature $\left({ }^{\circ} \mathbf{C}\right)$ & Ramp time (sec.) & Hold time (sec.) & Gas type \\
\hline 1 & 40 & 2.0 & 1.0 & Inert \\
\hline 2 & 120 & 5.0 & 10.0 & Inert \\
\hline 3 & 130 & 5.1 & 10.0 & Inert \\
\hline 4 & 400 & 5.0 & 10.0 & Inert \\
\hline 5 & 400 & 0.0 & 2.0 & None \\
\hline 6 & 2,000 & 1.0 & 1.5 & None \\
\hline 7 & 2,500 & 1.0 & 2.0 & Inert \\
\hline
\end{tabular}


inert gas at $300 \mathrm{ml} / \mathrm{min}$ (drying and ashing) except during the atomization step, the flow was stopped and 2,500 $\mathrm{ml} / \mathrm{min}$ while cleaning condition.

\section{Chemicals and Reagents}

In the analysis we used ultrapure water Type $1\left(\mathrm{UP} \mathrm{H}_{2} \mathrm{O}\right)$ with minimum resistivity of $18.2 \mathrm{M} \Omega . \mathrm{cm}$. Other chemicals were nitric acid (trance metal grade - TMG $\mathrm{HNO}_{3}$ ) and standard (SigmaAldrich: $\mathrm{Pb}$ ) for AAS with concentration of lead 1,000 mg/l. As the modifier we used $0.05 \% \mathrm{Pd}\left(\mathrm{NO}_{3}\right)_{2}+0.03 \% \mathrm{Mg}\left(\mathrm{NO}_{3}\right)_{2}$ (used in similar studies, and providing appropriate calibration curve) (10). Chemical modifier solution was prepared by appropriate dilution from $10 \mathrm{~g} / 1 \mathrm{Pd}\left(\mathrm{NO}_{3}\right)_{2}$ (VHG-MPDN1P-100) and $10 \mathrm{~g} / 1$ $\mathrm{Mg}\left(\mathrm{NO}_{3}\right)_{2}$ stock solutions (VHG-MPM3-250). Before analysis all the laboratory equipment (plastic bottles, autosampler cups, glass-ware materials etc.) were cleaned by soaking in $10 \%$ nitric acid for 24 hours. Then laboratory equipment was washed twice with UP $\mathrm{H}_{2} \mathrm{O}$. The standard for lead was diluted to $26 \mu \mathrm{g} / 1$ (max. recommended concentration by AAS manufacturers). The standard was always diluted before measurement. Blank was prepared from $\mathrm{UP} \mathrm{H}_{2} \mathrm{O}$.

Lead level concentration is expressed in $\mu \mathrm{g} / \mathrm{l}$. Concentration levels are presented as geometric mean, median and range. Limit of detection (LOD) and limit of quantification (LOQ) were different for each sample considering various dilution level (to achieve the same ethanol concentration before mineralisation). The limits were in the following intervals: LOD: 9.1-15.9 $\mu \mathrm{g} / \mathrm{l}$, LOQ: $30.3-53.1 \mu \mathrm{g} / \mathrm{l}$.

\section{RESULTS}

Lead was detected in all samples of fruit spirits (Table 3). In two cases, the concentration was lower than the limit of quantitation (LOQ). The highest observed concentration of lead was found out in the sample of plum spirits from Hungary (geometric mean $581.0 \mu \mathrm{g} / \mathrm{l}$; range $576.4-585.6 \mu \mathrm{g} / \mathrm{l})$ and in the sample of grape spirit made in Trnava (geometric mean $466.3 \mu \mathrm{g} / \mathrm{l}$; range $457.6-475.2 \mu \mathrm{g} / 1)$.

\section{DISCUSSION}

Our results, in accordance with other available published data (11-15), suggest that the lead is a common contaminant of fruit distilled spirits for own consumption. Nowadays, European data about lead content in fruit spirits are rather heterogeneous because they are not result of the systematic mapping of this issue. On the other hand, there are some studies from European countries such as Ukraine (4), Romania $(13,14)$ and Serbia (15), which reported similar lead concentration in fruit distilled spirits for own consumption and these results corresponded with our findings of lead concentrations. Similarly, as in the previous studies, we found out that the lead concentration in fruit spirits for own consumption may vary considerably. For example, some factors including fermentation quality, material of the distillation apparatus and containers for storage of the final products are very important (15). Although many authors point out the role of different type of the fruit on lead content in spirits (15), our results do not show

Table 3. Results for $\mathrm{Pb}(\mu \mathrm{g} / \mathrm{l})$ concentration in spirits

\begin{tabular}{|c|c|c|c|c|c|c|}
\hline \multirow{2}{*}{ Distilled fruits } & \multirow{2}{*}{ Country } & \multirow{2}{*}{ City } & \multirow{2}{*}{ Ethanol (\%) } & \multicolumn{3}{|c|}{ Concentration of $\mathrm{Pb}(\mu \mathrm{g} / \mathrm{l})$} \\
\hline & & & & Geometric mean & Median & Range \\
\hline Grape & Slovakia & Trnava & 46.9 & 179.8 & 180.0 & $172.4-187.6$ \\
\hline Grape & Slovakia & Trnava & 42.4 & 466.3 & 466.4 & $457.6-475.2$ \\
\hline Apples and plums & Slovakia & Martin & 52.8 & 69.4 & 69.4 & $69.3-69.5$ \\
\hline Apple & Slovakia & Martin & 66.5 & 108.8 & 109.0 & $102.3-115.7$ \\
\hline Apple & Slovakia & Martin & 66.5 & 102.9 & 103.0 & $98.6-107.4$ \\
\hline Apple & Slovakia & Žilina & 61.6 & 68.3 & 68.3 & $67.8-68.8$ \\
\hline Apple & Slovakia & Žilina & 58.1 & 85.9 & 86.0 & $81.7-90.3$ \\
\hline Apple & Slovakia & Martin & 54.1 & $<43.2^{*}$ & & \\
\hline Apple & Slovakia & Martin & 55.0 & 139.9 & 140.0 & $133.9-146.1$ \\
\hline Apple & Slovakia & Martin & 51.0 & 43.3 & 43.3 & $41.5-45.1$ \\
\hline Apple & Slovakia & Trnava & 51.5 & 153.9 & 154.0 & $148.3-159.7$ \\
\hline Apricot & Slovakia & Martin & 39.6 & 160.0 & 160.0 & $159.6-160.4$ \\
\hline Plum & Slovakia & Kysucké Nové Mesto & 60.0 & $<47.9^{*}$ & & \\
\hline Plum & Slovakia & Martin & 38.0 & 47.3 & 47.3 & $47.2-47.4$ \\
\hline Plum & Slovakia & Martin & 38.1 & 50.0 & 50.0 & $49.6-50.4$ \\
\hline Plum & Hungary & Győr & 55.7 & 581.0 & 581.0 & $576.4-585.6$ \\
\hline Blackthorn & Slovakia & Kysucké Nové Mesto & 55.8 & 216.0 & 216.0 & $215.1-216.9$ \\
\hline Blackthorn & Slovakia & Kysucké Nové Mesto & 57.3 & 121.8 & 122.0 & $115.5-128.5$ \\
\hline
\end{tabular}

${ }^{*}<\mathrm{LOQ}-$ lower than the limit of quantification 
any apparent association in this aspect. Anyway, these findings indicate that heavy metals in spirits for own consumption is a relevant public health issue.

Our results are interpreted in the context of the findings of other similar studies from developed countries (lower values concentration of lead in the environment and similar legislative) over the period 2007-2017. Until now, 10 studies (Table 4) similar to our one have been carried out in Europe. Lead levels in these studies ranged from ND (not detected by used methodology) to $2,500 \mu \mathrm{g} / \mathrm{l}$. Compared to results published by the International Agency for Research on Cancer (IARC), that identified values concentration of lead of up to $600 \mu \mathrm{g} / 1(16,17)$, relatively high values concentration of lead were found in spirits from Ukraine $(2,500 \mu \mathrm{g} / \mathrm{l})(4)$ and plum spirit from Romania $(800 \mu \mathrm{g} / \mathrm{l})(13)$. On the other hand, our results seem to be alike findings from Ukraine, Serbia and Romania regarding apple and plum spirits. Heavy metals, like lead, in these beverages can originate either from primary contamination of fermented fruit (e.g. from soil, water, pesticide, and fertilisers residuals etc.) or from secondary contamination occurring during distillation process and storing $(15,18)$. Therefore, a high number of possible above-mentioned factors can explain the heterogeneity of lead content identified in the beverages $(15,18)$.

Lead is classified by IARC as Group 2B (possibly carcinogenic to humans). Moreover, IARC classifies ethanol in alcohol beverages as a human carcinogen (Group 1) (16). Compared to commercially distributed sprits, these types of beverages contain usually higher ethanol content, i.e. more than 40\% (5). According to some authors, higher ethanol concentration is supposed to multiply toxic effects of lead (2). In the study by Jurczuk et al. interaction between ethanol and lead was found. The study showed that ethanol increases lead absorption, distribution and accumulation in the organism (namely liver and kidney), as well as harmful effects of lead (9). However, we should keep in mind, that this concept is based only on results of the pilot experimental animal study in rats (5-9).

If we compare official statistical data of European countries, we can notice that the mortality rate due to selected alcoholattributable causes corresponds only partially with alcohol con-

Table 4. Measured levels of concentration of lead $(\mu \mathrm{g} / \mathrm{l})$ in selected alcoholic beverages

\begin{tabular}{|l|c|c|c|}
\hline Type of spirit & Country & $\begin{array}{c}\text { Concentration } \\
(\mu \mathrm{g} / \mathrm{l})\end{array}$ & References \\
\hline Orujo & Spain & $<$ LOD-1.49 & Vilar et al. (11) \\
\hline Anise & Spain & ${ }^{*}$ ND-6.00 & Jurado et al. (12) \\
\hline Spirit-Samohon & Ukraine & ${ }^{*}$ ND-2500.00 & Lachenmeier et al. (4) \\
\hline Plum & Romania & $29.00-800.00$ & Rusu et al. (13) \\
\hline Plum & Romania & $<50.00$ & Gogoasa et al. (14) \\
\hline Cherry & Romania & $<50.00$ & Gogoasa et al. (14) \\
\hline Apple & Romania & $<50.00$ & Gogoasa et al. (14) \\
\hline Pear & Romania & $<50.00$ & Gogoasa et al. (14) \\
\hline Plum & Serbia & $<96.00-340.00$ & Bonic et al. (15) \\
\hline Apple & Romania & $151.00-246.00$ & Rusu et al. (13) \\
\hline
\end{tabular}

${ }^{*} \mathrm{ND}$ - not detected by used methodology; LOD - limit of detection sumption. For example, alcohol consumption in Slovakia (males, only drinkers aged $15+$ ) is higher than in Hungary, however, alcohol-attributable liver cirrhosis mortality rate in Hungary (males) considerably dominates. The similar discrepancies can be found also in other countries $(5,19)$. So it seems that apart from intensity of alcohol consumption, there are other factors playing a significant role in the development of health disorders and their occurrence in a population. In this context, several authors pointed out the potential effect of selected heavy metals enhancing effects of ethanol. Measured levels of concentration of lead and other heavy metals in alcoholic beverages were also published in IARC monographs, where lead concentration levels varied considerably in different types of alcoholic beverages (beer, wine and spirits) with the highest lead levels in alcoholic beverages containing more than $40 \%$ of ethanol (spirits) $(16,17)$.

Small number of analysed samples presents one possible limitation of our study. It was carried out as a pilot study and its main objective was to determine the presence of lead in samples of fruit spirits intended for own consumption. The results indicate a higher content in the grape spirits which calls for a deeper analysis as we need to know the association between the type of fruits, locality and lead concentration in spirit.

\section{CONCLUSIONS}

Our results indicate that the lead is a common contaminant in fruit distilled spirits for own use. Considering the widespread use of these types of alcohol beverages, this may become potentially relevant public health issue (if not kept under control). Due to insufficient information in this field, our results represent a significant insight into the issue and present an important starting point for further research in this field. To better understand the role of lead contamination of fruit spirits in alcohol-attributable morbidity and mortality future systematic research is needed.

\section{Acknowledgements}

This work was supported by grant UK/71/2017 from the University of Comenius in Bratislava.

\section{Conflicts of Interests}

None declared

\section{REFERENCES}

1. Wani AL, Ara A, Usmani JA. Lead toxicity: a review. Interdiscip Toxicol. 2015 Jun;8(2):55-64.

2. Rehm J, Kailasapillai S, Larsen E, Rehm MX, Samokhvalov AV, Shield $\mathrm{KD}$, et al. A systematic review of the epidemiology of unrecorded alcohol consumption and the chemical composition of unrecorded alcohol. Addiction. 2014 Jun;109(6):880-93.

3. Lachenmeier DW, Ganss S, Rychlak B, Rehm J, Sulkowska U, Skiba $\mathrm{M}$, et al. Association between quality of cheap and unrecorded alcohol products and public health consequences in Poland. Alcohol Clin Exp Res. 2009 Oct;33(10):1757-69.

4. Lachenmeier DW, Samokhvalov AV, Leitz J, Schoeberl K, Kuballa T, Linskiy IV, et al. The composition of unrecorded alcohol from eastern Ukraine: is there a toxicological concern beyond ethanol alone? Food Chem Toxicol. 2010 Oct;48(10):2842-7.

5. Lachenmeier DW, Monakhova YB, Rehm J. Influence of unrecorded alcohol consumption on liver cirrhosis mortality. World J Gastroenterol. 2014 Jun 21;20(23):7217-22. 
6. Gupta V, Gill KD. Influence of ethanol on lead distribution and biochemical changes in rats exposed to lead. Alcohol. 2000 Jan;20(1):9-17.

7. Flora SJ, Tandon SK. Effect of combined exposure to lead and ethanol on some biochemical indices in the rat. Biochem Pharmacol. 1987 Feb 15;36(4):537-41

8. Flora SJ, Gautam P, Kushwaha P. Lead and ethanol co-exposure lead to blood oxidative stress and subsequent neuronal apoptosis in rats. Alcohol Alcohol. 2012 Mar-Apr;47(2):92-101.

9. Jurczuk M, Moniuszko-Jakoniuk J, Brzóska MM. Involvement of some low-molecular thiols in the peroxidative mechanisms of lead and ethanol action on rat liver and kidney. Toxicology. 2006 Feb 15;219(1-3):11-21.

10. Caldas NM, Oliveira SR, Neto JA. Feasibility of internal standardization in the direct and simultaneous determination of $\mathrm{As}, \mathrm{Cu}$ and $\mathrm{Pb}$ in sugarcane spirits by graphite furnace atomic absorption spectrometry. Anal Chim Acta. 2009 Mar 16;636(1):1-5.

11. Vilar M, Barciela J, García-Martín S, Peña RM, Herrero C. Comparison of different permanent chemical modifiers for lead determination in Orujo spirits by electrothermal atomic absorption spectrometry. Talanta. 2007 Mar 15;71(4):1629-36.

12. Jurado JM, Martín MJ. Pablos F, Moreda-Piñeiro A, Bermejo-Barrera P. Direct determination of copper, lead and cadmium in aniseed spirits by electrothermal atomic absorption spectrometry. Food Chem. 2007;101(3):1296-304.

13. Rusu TE, Socaciu C, Părău C, Mocan AA. Quality and safety analysis for some traditional homemade fruit distillates from Transylvania (North
West Romania). Bull Univ Agric Sci Vet Med Cluj-Napoca Agric. 2010;67(2):395-403.

14. Gogoasa I, Rivis A, Velciov A, Gergen I. Heavy metals as potential contaminants of different assortments of fruit brandy in the Banat Area. J Horticult Forestry Biotechnol. 2013;17(3):134-6.

15. Bonić M, Tešević V, Nikićević N, Cvejić J, Milosavljević S, Vajs V, et al. The contents of heavy metals in Serbian old plum brandies. J Serbian Chem Soc. 2013;78(7):933-45.

16. IARC Working Group on the Evaluation of Carcinogenic Risks to Humans. Alcohol consumption and ethyl carbamate. IARC Monogr Eval Carcinog Risks Hum. 2010;96:3-1383.

17. Lachenmeier DW, Przybylski MC, Rehm J. Comparative risk assessment of carcinogens in alcoholic beverages using the margin of exposure approach. Int J Cancer. 2012 Sep 15;131(6):E995-1003.

18. Ibanez JG, Carreon-Alvarez A, Barcena-Soto M, Casillas N. Metals in alcoholic beverages: A review of sources, effects, concentrations, removal, speciation, and analysis. J Food Compost Anal. 2008 Dec;21(8):672-83.

19. World Health Organization. Global status report on alcohol and health 2014. Geneva: WHO; 2014.

Received September 4, 2018 Accepted in revised form April 24, 2019 